\title{
Sobre 0 diagnóstico da candidíase vaginal
}

\author{
The diagnosis of vaginal candidiasis
}

\author{
José Antonio Simões
}

A candidiase vaginal $(\mathrm{CV})$ continua sendo extremamente comum, uma vez que quase todas as mulheres experimentam esse desagradável quadro genital pelo menos uma vez em algum momento de suas vidas. A grande maioria das cepas isoladas da vagina correspondem a espécies da $C$. albicans, estimando-se que a proporção de infecções por cepas não-albicans venha aumentando progressivamente nos últimos anos. Clinicamente ambas são indistinguíveis, causando sintomatologia muito semelhante. Todavia, tem sido relatado que a $C$. albicans está mais associada com os sintomas do que as cepas não-albicans, as quais geralmente são mais resistentes às terapias habituais.

Com o objetivo de avaliar a distribuição de espécies de leveduras isoladas da vagina e o perfil de susceptibilidade in vitro das mesmas aos antifúngicos habituais, Ferrazza et al. ${ }^{1}$ publicaram em número recente desta revista os resultados de estudo com 227 mulheres em duas localidades no sul do Brasil. A freqüência de cultura positiva foi de aproximadamente $24 \%$, confirmando ser a $C$. albicans a mais prevalente. Entretanto, encontraram uma considerável diferença na proporção de cepas não-albicans, sendo muito mais freqüentes em uma das cidades e sugerindo diferenças regionais quanto à espécie isolada. Além disso, encontraram uma maior tendência de resistência à nistatina, sendo que praticamente metade das cepas apresentaram susceptibilidade dose-dependente (intermediária) a este anti-fúngico. A sugestão desses autores é de que seja realizada a determinação da espécie através de cultura e anti-fungigrama no manejo clínico da CV.

Acreditamos, no entanto, que isso seria inviável para nossa realidade e até mesmo desnecessário na grande maioria das vezes, devendo ser reservado apenas para aqueles casos da atualmente denominada CV complicada. Cremos, sim, que o diagnóstico correto de uma CV seja de extrema importância, e para o qual alguns pontos devem ser ressaltados para a prática diária, particularmente no sentido de se evitar o tratamento excessivo e equivocado dessa vulvovaginite.

A C. albicans é freqüentemente o diagnóstico presuntivo para qualquer irritação vulvovaginal. A maioria das mulheres e dos próprios ginecologistas assume erroneamente que todo e qualquer prurido genital, especialmente quando acompanhado por um corrimento vaginal, seja causado invariavelmente por uma candidíase. É preciso cuidado, pois esta idéia/crença não é verdadeira. Nossa experiência tem mostrado que pelo menos metade das mulheres que nos são encaminhadas com o rótulo de portadoras de CV recorrente (CVR), na verdade, têm seus sintomas devidos a outras causas que não a candidíase. Por isso, um diagnóstico correto é a maior garantia para o sucesso terapêutico.

Podemos, na prática diária, distinguir três tipos de mulheres com candidíase no nosso consultório: 1) aquela em que a cândida foi um achado ocasional no exame rotineiro de Papanicolaou; 2) aquela que nos procura por estar sintomática, porém sem história de recorrências (CV nãocomplicada); e 3) aquela que se apresenta com história de episódios recorrentes de candidíase (CV complicada). No primeiro caso, não devemos nos esquecer que a cândida pode ser isolada em até $30 \%$ das mulheres saudáveis e completamente assintomáticas (as chamadas "portadoras sãs"). Assim, o simples achado da cândida num exame de rotina (por exemplo no Papanicolaou) não significa necessariamente que a mulher tenha a doença candidiase vaginal clínica. Se não houver nenhum sintoma e o exame ginecológico for normal (sem corrimento ou inflamação, pH normal e teste de whiff negativo), a paciente não deve receber nenhum tratamento, a não ser uma boa orientação a respeito dos fatores predisponentes.

Professor Doutor de Ginecologia do Departamento de Tocoginecologia da Faculdade de Ciências Médicas da Universidade Estadual de Campinas UNICAMP - Campinas (SP) - Brasil

Correspondência: José Antonio Simões

Cidade Universitária Zeferino Vaz - Barão Geraldo - Caixa Postal 6181 - 13083-970 - Campinas-SP - (19) 3289-2856/3788-9306/3289-2440 -

3788-9306 (CAISM) - jsimoes@caism.unicamp.br 
A cândida é um microorganismo dimórfico, e pode ser tido como comensal ou patogênico, na dependência dos seus fatores próprios de virulência e dos fatores de defesa do hospedeiro. Para que ocorra a candidíase vaginal clínica, o fungo precisa vencer a batalha com o meio vaginal e invadir a mucosa, causando sintomatologia. Geralmente isso é favorecido por alguns fatores classicamente reconhecidos como predisponentes para a CV: gravidez, uso de anticoncepcionais orais de alta dosagem, diabete melito descompensado, uso de corticóides, imunossupressores e antibióticos. Rosa e Rumel ${ }^{2}$, também em recente publicação nesta revista, associaram a CV com ciclos menstruais normais. Além disso, com alterações na resposta imunológica, hábitos de higiene e vestuário inadequados, e contatos com alergenos e/ou irritantes da genitália.

No segundo caso, a CV não-complicada é causada pela C. albicans e ocorre em mulheres não comprometidas imunologicamente e com infecção leve ou moderada, e sem história de recorrências. O diagnóstico é sugerido clinicamente pela presença de prurido, corrimento vaginal e eritema, os quais, todavia, não são específicos da CV. Por isso, nunca se deve tratar sem ao menos examinar a mulher. Nunca se deve tratar sem exame físico prévio ou baseado apenas na queixa. Outras causas (infecciosas ou não) também podem levar a esses mesmos sintomas. Embora o corrimento seja descrito tipicamente como tipo "leite coalhado", ele pode ser extremamente variável, ou até muito discreto. O exame freqüentemente revela vulva e vagina bastante hiperemiadas, às vezes edemaciadas e com fissuras. Deve-se sempre tentar a confirmação diagnóstica através da microscopia (a fresco, com KOH a 10\% ou corada pelo Gram), que mostra a presença do fungo (leveduras e/ou pseudo-hifas). O $\mathrm{pH}$ vaginal apresenta-se normal $(\leq 4,5)$. A cultura e anti-fungigrama não são necessários nesses casos não complicados, uma vez que praticamente todos eles são causados pela C. albicans.

Finalmente, a CV complicada (recorrente) refere-se àquelas infecções mais severas incluindo as causadas por espécies não-albicans, geralmente em mulheres com história de CVR e/ou com algum tipo de imunodeficiência. Ocorre em aproximadamente 10-20\% das mulheres, as quais merecem considerações especiais, e continua sendo uma das principais "pedras nos sapatos" dos ginecologistas. A primeira questão que deve ser feita nos casos que se apresentam como CVR é: será que realmente trata-se de uma CVR? Uma grande parte das mulheres que nos chegam rotuladas como portadoras de CVR têm, na verdade, seus sintomas devidos a outras etiologias, geralmente não-infecciosas (alergia, hipersensibilidade local, vaginose citolítica, etc.). Portanto, acreditamos que nesses casos de CVR, sim, o diagnóstico da candidíase deve sempre ser confirmado por meio de cultura vaginal específica (em meio de Sabouraud). Além de confirmar o diagnóstico clínico, a cultura específica determina a espécie de cândida envolvida e permite a realização dos testes de susceptibilidade, que pode ser importante nesses casos recorrentes.

\section{Referências}

1. Ferrazza MHSH, Maluf MLF, Consolaro MEL, Shinobu CS, Svidzinski TIE, Batista MR. Caracterização de leveduras isoladas da vagina e sua associação com candidíase vulvovaginal em duas cidades do sul do Brasil. Rev Bras Ginecol Obstet. 2005;27(2):58-63.

2. Rosa MI, Rumel D. Fatores associados a candidíase vulvovaginal: estudo exploratório. Rev Bras Ginecol Obstet. 2004;26(1):65-70. 